\title{
Experience of Innovative Technologies Application in the Training for IT Professionals
}

\author{
N. Y. Ershova, A. I. Nazarov, O. V. Sergeeva, and A. V. Soloviev
}

\begin{abstract}
The paper presents practice of methods and techniques application on the basis of standard and specialized e-learning platforms, other communication and programming tools. The discussed methods intensify students' activity, selfdependence and active curiosity in achieving high results in the process of learning due to network educational module use.
\end{abstract}

Index Terms-E-learning system, IT professionals, network educational module, network education system, Blackboard Learn platform, score rating system.

\section{INTRODUCTION}

Russian economy will lack over 30 thousand IT system technicians in 2013 and more than 50 thousand in 2015 - this was the conclusion made in the course of the research which was conducted by order of the industry association of computer and IT enterprises [1]. With further innovative development of the economy the gap between the number of working IT specialists and staffing requirements will be increasing. Moreover, in addition to the lack of qualified specialists in this field a problem of their high-quality training will emerge.

In the monograph [2] the quality of training is determined by the assembly of the following elements: the students enrolled, students' learning activity, students' professional training, quality of teaching, content of education and educational technologies. Students' qualitative composition is one of the input parameters for a system of education. It characterizes the contingent of first-year students and can be determined through their awareness of profession selection, applicants' motivation level, grade point average (GPA) at the Unified State Examination, etc.

Annual questioning of first-year students at Petrozavodsk State University shows that an applicant is often guided by

Manuscript received November 25, 2013; revised December 5, 2013, accepted December 10, 2013. Date of online publication: December 15, 2013.

The article is prepared within the Program of Petrozavodsk State University Strategic Development for 2012-2016.

N. Y. Ershova and A. V. Soloviev are with the Department of Information Measuring Systems and Physical Electronics, Faculty of Physical Engineering of Petrozavodsk State University, 185910 Petrozavodsk, Russia (e-mails: ershova@psu.karelia.ru, avsolov@plasma.karelia.ru).

A. I. Nazarov and O. V. Sergeeva are with the Department of General Physiscs Faculty of Physical Engineering of Petrozavodsk State University, 185910 Petrozavodsk, Russia (e-mails: anazarov@petrsu.ru, osergeeva@petrsu.ru). parents' or friends' advice and is motivated by high salary in the chosen profession, thus high or average GPA does not guarantee high grades at the end of the term.

To improve the situation we should not just take measures to increase applicants' motivation: invite successful students and alumni; provide information about their future professional activities; stimulate them; apply a score-rating system and so on, but to review the content of educational courses and the form of their presentation.

\section{DEVELOPMENT OF THE E-LEARNING SYSTEM}

The content of educational material substantially determines the educational process results. High quality of the content is one of the necessary conditions to achieve results of high quality. However, if training organization, its methods and tools are not efficient, such results cannot be achieved. Moreover, instructors' qualification substantially affects the training results. We should bear in mind that it is the information and communication competence of an instructor that serves as the basis of their professional competence in conditions of fast IT development.

At present the system of higher education is starting to employ the resources which are provided by information and network technologies and by innovative pedagogy achievements. These trends are observed in the Federal law «Education in the Russian Federation» which came into legal force since September, 1, 2013. The new law set forth such concepts as «electronic educational technologies», «network forms of educational programs implementation».

Application of these innovations in the higher school affects all components of the educational process and requires significant reconsideration of content, educational technologies and methods, integration of learning and research activities. Transition to e-learning technologies application in educational process was gradual at the faculty of technical physics in PetrSU. Separate digital educational resources (lecture notes, computer models, animation applications, video clips) were developed at the first stage. Then these resources were put together into systems for e-learning [3], [4].

At present e-learning system at the faculty of technical physics is implemented basing on the concept of open education and network technologies resources [5]. Modular construction of basic educational programs (BEP) as well as of the content of learning and methodical complexes of courses together with ICT resources predetermined the necessity of 
transition from e-learning technologies to a network form of educational programs implementation [6].

The concept of open education as innovation in the field of theory and methods of education arose at the beginning of the XXI century due to fast development of information and communication technologies. Efficient implementation of open education principles [7] and transition to the network form of educational programs implementation can be achieved on the basis of network education technologies. According to the authors' opinion, network education implies a complex organization of the educational process accomplished through application of information technologies and based on the principles of open education in an electronic information environment, a score - rating system application in students' learning activity assessment, means of operative knowledge testing, technologies of long-distance and distributed experiment implementation.

The following tasks have priority: organization and support of students' self-education, support of interactive practical education, development of methodical and informational support for an adaptive stage which is necessary for students with low initial level of training in physics. We should take into consideration students' preferences in receiving and working with information which is usually presented in the electronic form. The fact that information technologies are both a subject to learn and the means of education for students earning their bachelor's degree in IT is very important.

\section{IMPLEMENTATION OF E-LEARNING SYSTEM IN TEACHING AND LEARNING SUBJECTS OF NATURAL AND MATHEMATICAL SCIENCES}

Let's consider the organization of the educational process within a network education system. We will analyze the system of bachelor's training in the field of information technologies at the Faculty of Physical Engineering.

We propose to use a network educational module (NEM) as a unit for network implementation of BEP. First let's consider the structure, content and methods of work with the network educational module through the example of the course «Mechanics and molecular physics» which is included into block B1 of natural and mathematical subjects for a bachelor degree course, and then we will demonstrate the technique of NEM and e-learning technologies application in a master degree course "Informatics and computer science".

Network educational modules in physics developed by the Chair of general physics are mainly focused on supporting a full-time course of study with network technologies resources and students' self-work organization on the e-learning platforms Webct and Blackboard Learn (Fig. 1). The NEM in physics can be considered both as a basic module and an expanded one for IT bachelor degree program. The basic level of NEM is aimed at minimum volume of physics to study, and the extended one is aimed at programs with more credits for this subject [8].

The structure of NEM in physics includes the following structural elements (blocks): 'necessary information', 'information', 'work with the course', 'communication', 'management'.

The structural element 'necessary information' includes home page, personalized by an instructor and a student according to their preferences, tools 'announcements' and 'calendar'. The latter can be used by an instructor and students as an individual tool and as one of the tools to specify the work with NEM. In the calendar an instructor specifies the deadlines for the assignments which are graded manually. References for the assignments which are graded automatically appear in the calendar as soon as their deadlines are approaching.

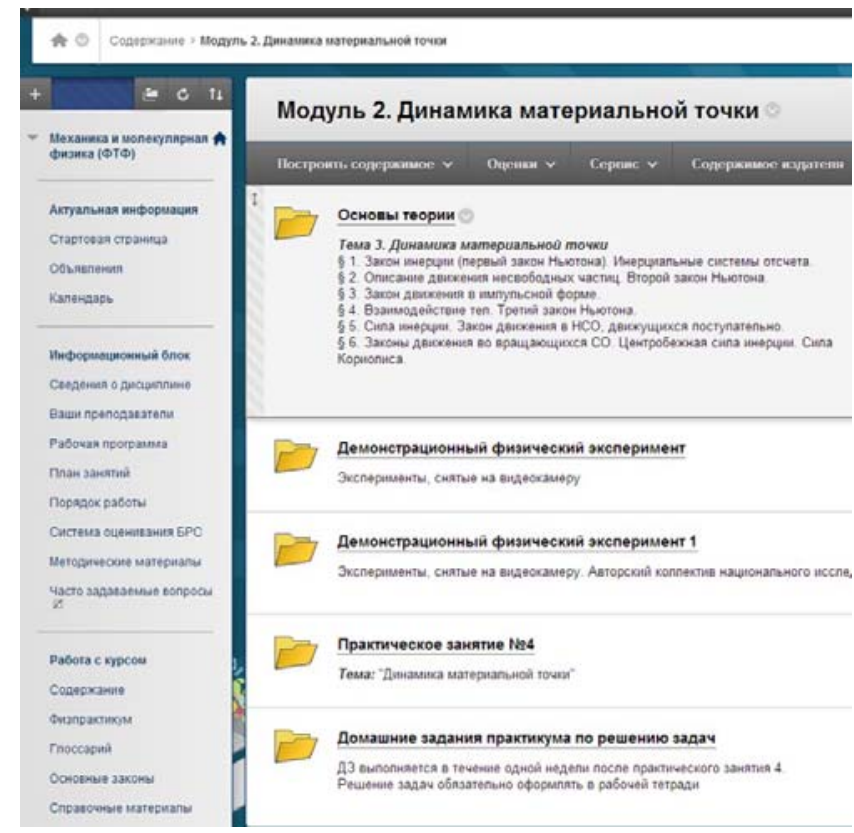

Fig. 1. A fragment of NEM «Mechanics and molecular physics».

The block 'information' includes general information about the course (working program of the subject, information about the instructors, course structure and working hours required for its acquisition, schedule, operating instruction for NEM, information about score-rating system, questions to be studied before the examination, lists of basic and supplementary literature), individual timetables of laboratory work, resource materials.

The block 'work with the course' includes: topical modules 'content' and 'physical practicum', educational elements 'glossary', 'basic laws', 'reference materials', 'learn more', 'educational tasks' and 'my grades'. To accelerate the access to separate materials the block is supplied with references to 'homework' and 'control work' presented as tests, entrance and final tests.

The content of topical modules is connected with chapters of the bachelor degree subject, and the modules functionally combine a complete cycle of students' work [3]. Each topical module consists of the following learning units: theoretical basics; demonstrational experiment; practical lessons; homework; references to digital resource materials.

The learning unit 'theoretical basics' includes an 
introduction to a lecture, extended lecture notes, lecture presentation and multimedia applications (video clips, animations, computer models, etc).

The first page of each of 10 topical modules presents the content of its theoretical part. This helps students to acquire the subject structure and to clarify the interrelation between separate paragraphs. The introduction gives short information about the topic, provides some interest stimulating material, and demonstrates its importance for physics and engineering.

The extended lecture notes are composed as an electronic textbook. This module helps students reach high level of self directed work and activity in acquiring theoretical knowledge. In particular, they can work with the material of various levels of difficulty and content; use various forms of its presentation (text, figures, graphs, animations, computer models, video demonstrations of physical experiments); choose and personalize information resources; discuss; supplement the considered material with digital material from the open educational environment.

The learning module 'practical lessons' includes the following elements: the purpose of the lesson; questions for self directed work; brief theoretical notes; recommendations for tasks solution; tasks to be considered in class in case of full-time form of education. The tasks have a detailed solution to help students in their independent work at home. If a student misses the lesson he should learn the unit material on his own.

Two first components of the module 'practical lessons' are aimed at organizing students' self - directed work. Students do computer tests during the week before the lesson. In class the students have to answer questions in oral or written form at the beginning of the lesson. Then students refresh the basic information given in the learning unit 'theoretical basics', after that they discuss algorithms and recommendations for task solution with the help of the instructor. Then they start to solve the tasks which are considered as the examples of the learned theoretical material.

Students' activity level in class is assessed by the instructor and is included as one of the parameters of a score rating system in grading the results of student's current work. Practical lessons are held in a computer class with an interactive board. This increases the efficiency of work, reducing the time for necessary resources access and helps to illustrate the lecture material.

The lesson outline considered above is a basic one. Students can be offered video tasks [9] or asked to work with network information and education resources as individual or group task to stimulate their learning activity.

The learning unit 'homework' includes the tasks aimed at reinforcing the material learned in class. The tasks are presented as various tests: multiple choice tests, tasks with variable numeric parameters, tasks with calculated results; correlation tasks. Success in tasks fulfillment is evaluated in scores. Homework should be done during one week after the corresponding practical lesson. The results of homework are graded according to the score rating system.

The learning unit 'glossary' includes the basic definitions and laws. References are made at the brief variant of the electronic textbook. This unit together with the unit 'theoretical basics' can be used as the resource for operative access to the course information and help in knowledge systematization. The unit 'reference materials' presents tables of integrals and derivatives, values of physical constants, rules of work with vectors, Greek alphabet, etc.

The learning unit 'learn more' offers materials for students' self directed work. As a rule they are additional electronic educational resources developed by professors of other universities, references to interesting applications of physics in science and engineering.

The module 'physical practicum' is an independent unit and is composed according to the cycles in which the content similarity of the studied material is presented, for example, conservation laws, mechanical oscillations, laws of classical thermodynamics, etc. Physical practicum is an obligatory component of modern science study. Educational or scientific experiments differ from other ways of acquiring scientific knowledge by the stage of obtaining and processing experimental data. As a rule students gain the skills of dealing with experimental equipment, study techniques of experiment setting and processing its results.

Students studying bachelor degree program «Informatics and computer sciences» have additional opportunities to gain skills in working with measuring equipment, information storage and processing. This is possible due to, first, wide integration of computers into integrated information and measuring devices; second, a computer application as a means of information processing; third, due to information transfer from a measuring device (a sensor) to a signal processing device through wired and wireless networks. Physical practicum tasks are conducted in the laboratories of the Chair of general physics, PetrSU at various degrees of computer use [10].

Undoubtedly, students conduct a natural experiment in the laboratory on their own. The learning unit 'physical practicum' includes educational resources and references to laboratory works carried out with a computer. The students' activity in physical practicum material learning is graded according to the criteria of the score rating system: readiness, report preparation and presentation. Students can view their grades per each type of activity in the proper section of Blackboard.

Students' work is regulated by the unit 'educational tasks'. The deadlines are given in the subject schedule automatically.

The learning unit 'tests' includes two control works, one independent work, two final tests. The latter are constructed on the basis of the federal task base which is used to control persisting knowledge in physics. The tasks in the tests are formed randomly from the created base of test tasks (pools). Test tasks are divided into topics thus allowing generation of a test with various topical tasks. The form in which the test tasks conditions are presented is similar to the one given in the learning unit 'homework'.

A student can control grades on his or her own from the unit 'my grades'. They can see their grades for some particular 
activities and the final grade; and monitor their advancement comparing them with the group's grades (an average grade and median for each activity are presented in the unit).

The unit 'communication' includes the following elements: your group, blackboard mail, e-mail, group journal, forums, on-line consultations [6]. The element 'your group' is an integrating one. It includes information about group classes timetable, discussion board, group journal, tools for files and messages exchange.

Communication is arranged through the tools 'blackboard mail' and 'e-mail'. Time delayed scheme of interaction between students and between students and instructors is implemented via forums. Forums are topical (students cannot open their own ones). The topics discussed are stored in the data base and both students and the instructor can access any necessary issue through the network, answer the question and make comments. Students' activity is assessed according to their ability to ask questions, the number of correct answers, and the frequency of their access to the forum.

'Group journal' is a tool for open forums. All members of the group (both students and the instructor) assess the usefulness of the discussed issues in the journal. On-line communication in the element 'consultation' is implemented through the tools 'chat' and 'video conference'.

Network educational module management and monitoring of acquisition of knowledge presented in the module are implemented through the block 'management' according to the score rating system. A complex of various types of learning activities is assessed: student's preparation for practical lessons, his active work in class and with NEM, tests and homework results, individual and group work, independent and control works results, physical practicum work results. Types of activities are normalized according to the Table I.

TABLE I

VARIOUS TYPES OF ACTIVITIES NORMALIZED ACCORDING TO THE SCORE RATING SYSTEM

\begin{tabular}{llcc}
\hline \hline \multicolumn{1}{c}{ Type of activity } & $\begin{array}{c}\text { Maximum } \\
\text { score }\end{array}$ & $\begin{array}{c}\text { Normalizing } \\
\text { coefficient } \\
\text { (unit weight) }\end{array}$ \\
\hline 1 & Physical practicum work results & 400 & 0.25 \\
\hline 2 & Homework results & 240 & 0.20 \\
\hline 3 & $\begin{array}{l}\text { Test results while preparing for practical } \\
\text { lessons }\end{array}$ & 80 & 0.08 \\
\hline 4 & Self guided work results & 90 & 0.08 \\
\hline 5 & Control work 1 & 80 & 0.08 \\
\hline 6 & Control work 2 & 80 & 0.08 \\
\hline 7 & $\begin{array}{l}\text { Final tests for the topics: «Mechanics» and } \\
\text { «Molecular physics» }\end{array}$ & 32 & 0.10 \\
\hline 8 & $\begin{array}{l}\text { Network interaction (participation in blogs, } \\
\text { group journal, discussion board, etc) }\end{array}$ & 120 & 0.05 \\
\hline 9 & Work at practical lessons & 340 & 0.08 \\
\hline & Maximum score for activities & & 1.00 \\
\hline
\end{tabular}

The final grade is given according to the results of current academic progress and examination. More details of the score rating system application in the network form of educational process arrangement are given in [6].

Here is some preliminary review of NEM application results made on the basis of 125 first year students' teaching experience during two months. Students were tested before they started working with NEM. Maximum score was 85 out of 100, average and median score - 50 and 51 respectively. The average score was lower than the GPA at Unified State Examination; this might be due to long summer vacations and low level of students' knowledge in physics.

About two thirds of students worked with NEM on a regular basis, they fulfilled the tests requiring minimal level of knowledge in physics at $70 \%$ in average. Homework tasks which were more difficult and required basic level of knowledge of the subject were fulfilled at $50 \%$. It is worth noting that the score rating system introduction motivated students for better academic progress compared with the last academic year, especially the students earning their bachelor's degree, who achieved the best results in the group.

Students majoring in Informatics and computer science showed their interest and made efforts in learning and preparing for physical practicum. However, $10 \%$ of students missed classes and were not able to do the tasks.

First experience results showed that students' network activity was low. Only about $20 \%$ of them communicated with the instructor via e-mail, but they practically did not participate in forums. Thus students' network interaction arrangement needs more elaboration.

After the first attempt to do the final test in «Mechanics» the average score and median increased and reached 60 and 63 respectively. The average score for students who tried to solve the problems but not to guess the answers was 70 . This fact indicates that there is some progress in knowledge acquisition in academic groups as a whole and that the motivated students achieve better results. The given results are just preliminary ones and could improve when the work with the NEM is completed.

Positive effect will be achieved as first year students get customized for the learning process at university which requires higher levels of their self guidance and work consistency abilities. This conclusion is supported by the fact that "weak" and especially "strong" students achieved better results when doing intermediate tests.

\section{E-LEARNING SyStem APPLICATION IN TEACHING VOCATIONAL SUBJECT}

Network educational module for the subject «Microprocessor based systems design» was developed at the Chair of information measuring systems and physical electronics in PetrSU and is aimed at students' self-guided learning through network technologies tools on the e-learning platform Blackboard Learn. Activities in studying theory and doing some laboratory works are performed in an online study mode. At an overview lecture an instructor explains the students what they must learn and how their results could be assessed. Class academic hours make less than $20 \%$ of the total subject workload.

Immediately before a student starts to learn the subject he and the instructor conclude an educational contract (EC). In 
the contract the student explicitly states:

- how he is going to study the material: methods and strategy of learning;

- resources to be used to study the material;

- in what way the student will demonstrate his knowledge;

- who will assess his results: the instructor or the group.

When the contract has been discussed with the instructor and authorized the student starts to work with NEM on his own. Contact hours are given:

- to defend the reports on laboratory practicum (2 reports, other reports are submitted in an electronic from);

- to make presentations on the subject topics;

- to defend individual projects.

Platform Blackboard Learn provides the instructor with wide opportunities for educational process control through various reports. For instance, a review of the course activity includes general data about the activities within one course sorted according to students' family names and dates (Fig. 2).

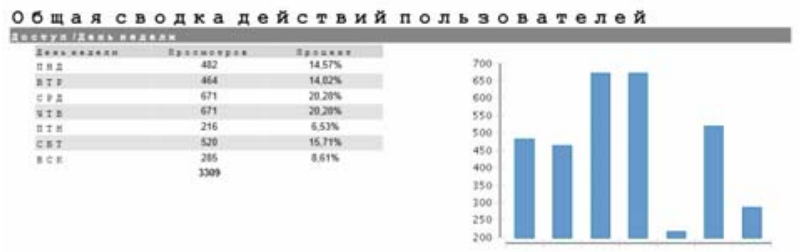

Fig. 2. General report on users’ activity.

At present students earning their master's degree are successfully fulfilling their educational contracts.

Besides standard ways of educational process organization the faculty of the Chair of information measuring systems and physical electronics in PetrSU use a special complex for educational support developed at the Chair [11] and titled «Complex of Multi-Purpose Outfit for Training \& Education (COMPOTE)». The complex includes:

- a system of students' remote login and unified passthrough desktop connection authorization, used for the systems listed below;

- e-mail service for students and instructors;

- file servers on the basis of distributes file system AFS;

- a system of on-line students' knowledge and skills testing iq.karelia.ru, awarded with a gold medal at the regional competition of the Internet resources of the North-West of the Russian Federation (Fig. 3);

- an automated system of students' attendance and academic progress recording "Conduits";

- a system of educational process maintenance (electronic notice board, electronic textbooks and other services);

- a system of publication recording;

- a system of Wi-Fi infrastructure support of the PetrSU corporate network segment in the campus of the Faculty of Physical Engineering.

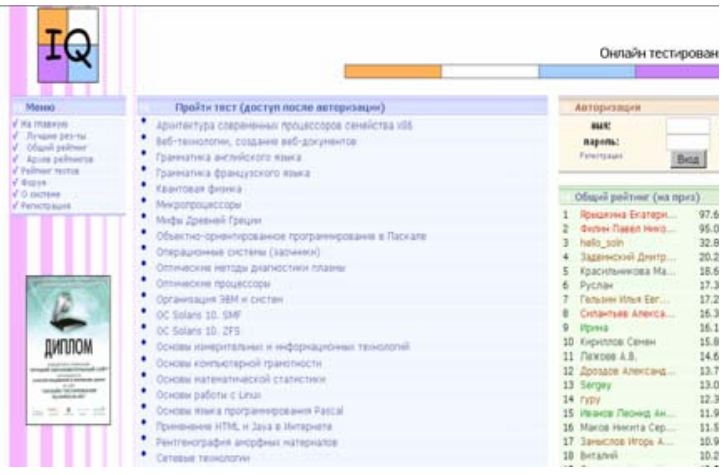

Fig. 3. System of on-line students' knowledge and skills testing (IQ).

The following tools of the complex are worth noting: the system of on-line students' knowledge and skills testing, the automated system of students' attendance and academic progress recording «Conduits» and the system of publication recording.

The system of on-line students' knowledge and skills testing is based on the following principles:

1. Transition from the truth assignment of the suggested answers variants in categories of binary logic ("correct incorrect") to a more general and universal scheme of assessing answers through the preference function determined in categories of fuzzy logic.

2. Quantitative determination of complexity and importance of each test task according to a proportional digital scale which enables to increase the objectiveness of the demonstrated knowledge assessment.

3. Fragmentation of test tasks collection into topical subcollections and compulsory ranking of all test tasks inside every subcollection.

The system provides the instructor with the opportunity to form various types of reports and to control student's progress through identifying his mistakes and using feedback; to analyze the most frequent mistakes, to detect gaps in students' knowledge in order to make some changes and clarifications in the material presentation. Feedback is performed via forum on site iq.karelia.ru.

Some special resources have been implemented to provide reliability and objectivity of test results, for example, a mode of a control test. As a rule students can do some preliminary tests in a self control mode and then do the control test in the exam mode in the presence of the instructor. Usually the test which is done in the exam mode has about one third of additional questions.

The instructor sets the date and time of the control test, a student logins in the system and is permitted to do the test after successful authorization. The number of attempts is set by the instructor. The time assigned for the answer is displayed on the page together with the question during the test. The maximum period of time is assigned by the instructor. Usually it is from one to three minutes (in case when a problem solution is required.)

The on-line test system provides the unified level of requirements and effective control of students' knowledge and 
motivates them for regular and fruitful learning.

Introduction of a module form of education is in good agreement with the score - rating system of students' achievements assessment within COMPOTE [12]. A special automated system «Conduits» (students' attendance and academic progress recording according to the score-rating system) included in the complex is aimed at improving the organization of the educational process and students' and instructors' discipline.

Due to the information system «Conduits» integration with the subsystem of students' remote login and authorization it is possible to control students' attendance and computers availability in on-line mode.

Interaction with the subsystem of on-line knowledge testing makes it possible to transfer the students' control tests results to the corresponding control points in «Conduits» at the instructor's request to increase students' score ratings.

A student can monitor the increase of the components for his final grade for the subject starting from the first week of studies and working with the system «Conduits» and at the end of his work with the module he is able to determine his final grade with the utmost probability. At the same time the instructor can vary the complexity and number of control points necessary for the progress in the subject material acquisition depending on the level of students' initial knowledge.

The system «Conduits» implements various presentations according to the characteristics of the subject - so called «conduit profiles». Besides the 'common' profile such profiles as «course work», «applications», «for students» have been introduced in the system. Last two profiles can be altered by the students themselves.

The profile «applications» is mainly aimed at arrangement of the course works topics selection process. Every year the third year students have to choose their academic advisor for their course work. Professors make lists of urgent problems to be solved in a separate conduit. A student after authorization can make an application for the topic he has chosen. All the authorized users can see who has made applications for any topic.

Another interesting profile in the «Conduits» is "a students' conduit" meant for the subjects which include writing a summary on the chosen topic as one of the steps of students' knowledge control. «Students' conduit» besides the common columns for attendance and academic progress includes a special column filled up by the student himself. After authorization a student can print a small text (for example, the topic of the summary) in this column opposite his name. The instructor has the opportunity to block these data input after some definite date. The advantages of such conduit are evident enough: students' mobility improvement and efficient provision of information for the instructor.

The system of publication recording (SPR) also included in the COMPOTE is a web application for multithreaded accumulation and processing of data about the university faculty and students publications. SPR provides access to the central data base of the faculty and students publications, an interface to enter new data and alter the existing ones. SPR is also designed to generate various reports and lists of publications. Due to the data central storage their presentation meets State Standards 7.1-2003 and 7.05-2008. The users can select data according to various attributes.

SPR provides new opportunities for the educational process besides office system automation of some processes (research reports generation). SPR is integrated into COMPOTE and the information about the student's achievements (his grades, ratings, course or qualifying papers) generated in the system "Conduits" is replenished with the data of his scientific publications. This information constitutes a student's portfolio.

\section{CONCLUSION}

Practice of the described above methods and techniques use on the basis of standard and specialized e-learning platforms and other communication and programming tools demonstrates growth of students' activity and self-dependence and their interest in achieving high results in the process of learning. This effect is caused, in particular, by the multiplicity of educational resources presented in NEM, by the informed choice mode of one's action, and, what is the most important, by the mechanism of personality self-alteration. Also it is caused by portfolio composition, by the individual trajectory of learning, by constant monitoring of educational results and academic progress of each student.

Dynamic implementation of modern programming tools and technologies, participation in the development of user's interfaces, models and components of program complexes and data bases both in the educational process and in research work should lead to shaping skills of practical activities in students earning their bachelor's degree in information technology and should improve the quality of education as a whole.

\section{REFERENCES}

[1] I. Agapov (2012, May 17). Russian innovative economy lacks ITprofessionals. [Online]. Available: http://marker.ru/news/524606.

[2] G. A. Bordovsky, A. A. Nesterov, and S. Y. Trapitsin, Educational process management, St. Petersburg: Herzen State Pedagogical University, 2001, 359 pages.

[3] N. Y. Ershova and A. I. Nazarov, Implementation of network education principles in the process of bachelors and masters training in the field of information technologies. Petrozavodsk: Petrozavodsk State University, 2012, 104 pages.

[4] A. I. Nazarov and S. D. Khanin, "Model of the open education system in physics," Open Education, no. 6(53), pp. 33-45, 2005.

[5] N. Y. Ershova and A. I. Nazarov, "Modern technologies of engineers training as the way of module education principle implementation," Open and distance education, no. 3(43), pp. 75-80, 2011.

[6] N. Y. Ershova, A. I. Nazarov, and M. A. Serezhina (2013). Realization of the basic principles of the organization of educational activity in the online learning. Distance and virtual education [Online]. 10, pp. 103114. Available: http://www.edit.muh.ru/content/mag/jour3.php?link= di102013.

[7] V. I. Soldatkin (ed.), Base of Open Education (2 volumes), Moscow: SEEC RAS Russian State Open Education Institute, 2002.

[8] N. M. Kozhevnikov, "Bulletin of scientific-methodological council in physics,” State Polytechnic University, St. Petersburg, no.4, 2012. 
[9] A. I. Skvortsov and A. I. Fishman, "Book of Video problems: from Observation to Measurement," Physics in Higher Education, vol. 10, no. 4, pp. 98-105, 2004.

[10] E. L. Kazakova and A. I. Nazarov, "Methodical Aspects of Information Technology Using in the Laboratories of Physical Practice Work," Physics in Higher Education, vol. 15, no. 3, pp. 86-95, 2009.

[11] A. V. Soloviev, "Web-application of attendance and academic progress recording Conduits," Certificate for the branch recording of the project
N 11705, no. 50200802234, filed 01.11.2008, published 05.12.2008, Innovations in Science and Education, no. 46, p. 1, 2008.

[12] N. Y. Ershova, S. A. Kiprushkin, and A. V. Soloviev, "Practice of modern pedagogical technologies use in computer science teaching," Open and Distance Education, no. 1(37), pp. 43-49, 2010. 